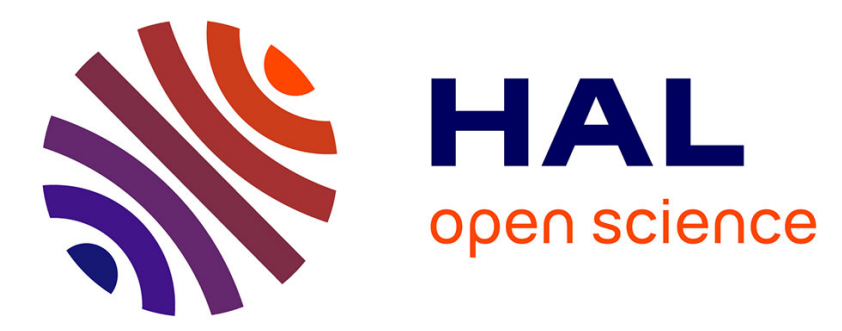

\title{
A calorimetric study of pTS (bis-p-toluenesulphonate of 2,4-hexadiyne 1,6-diol) and its phase transitions as a function of polymerization
}

\author{
M. Bertault, A. Collet, M. Schott
}

\section{- To cite this version:}

M. Bertault, A. Collet, M. Schott. A calorimetric study of pTS (bis-p-toluenesulphonate of 2,4hexadiyne 1,6-diol) and its phase transitions as a function of polymerization. Journal de Physique Lettres, 1981, 42 (6), pp.131-133. 10.1051/jphyslet:01981004206013100 • jpa-00231891

\section{HAL Id: jpa-00231891 https://hal.science/jpa-00231891}

Submitted on 1 Jan 1981

HAL is a multi-disciplinary open access archive for the deposit and dissemination of scientific research documents, whether they are published or not. The documents may come from teaching and research institutions in France or abroad, or from public or private research centers.
L'archive ouverte pluridisciplinaire HAL, est destinée au dépôt et à la diffusion de documents scientifiques de niveau recherche, publiés ou non, émanant des établissements d'enseignement et de recherche français ou étrangers, des laboratoires publics ou privés. 


\title{
A calorimetric study of pTS (bis-p-toluenesulphonate of 2,4-hexadiyne 1,6-diol) and its phase transitions as a function of polymerization (*)
}

\author{
M. Bertault ( $\left.{ }^{1}\right)$, A. Collet $\left({ }^{2}\right)$ and M. Schott $\left({ }^{1}\right)$ \\ (1) Groupe de Physique des Solides de l'Ecole Normale Supérieure (**), \\ Université Paris VII, Tour 23, 2, place Jussieu, 75221 Paris Cedex 05, France \\ $\left({ }^{2}\right)$ GR no 20 du C.N.R.S., College de France, 11, place Marcellin-Berthelot, 75221 Paris Cedex 05, France
}

(Reçu le 23 décembre 1980, accepté le 29 janvier 1981)

\begin{abstract}
Résumé. - On a mesuré la chaleur spécifique de pTS entre 135 et $225 \mathrm{~K}$, pour des taux de polymère $0 \lesssim \mathfrak{T} \lesssim 1$. Pour $\mathcal{T} \lessgtr 0,01$, deux endothermes entre 156 et $192 \mathrm{~K}$ limitent la phase incommensurable. Pour $0,01 \lessgtr \mathfrak{T}$ deux autres transitions s'y ajoutent vers 161 et $182 \mathrm{~K}$. Les enthalpies correspondantes diminuent de 25 à moins de $1 \mathrm{cal} . / \mathrm{mole}$ et les transitions cessent d'être observables à $\mathcal{T}>0,04(182$ et $192 \mathrm{~K})$ ou $0,12(150$ et $161 \mathrm{~K})$. Une transition est à nouveau observable vers $189 \mathrm{~K}$ pour $\mathfrak{T} \gtrsim 0,95$, avec $\Delta H \sim 10 \mathrm{cal} . / \mathrm{mole}$.
\end{abstract}

\begin{abstract}
The specific heat $C_{p}$ of pTS was measured from 135 to $225 \mathrm{~K}$, for polymer contents $0 \lesssim \mathfrak{T} \lesssim 1$. For $\mathcal{S} \lessgtr 0.01$, two endotherms near 156 and $192 \mathrm{~K}$ limit the incommensurable phase. For $\mathfrak{T} \gtrsim 0.01$, two other transitions occur near 161 and $182 \mathrm{~K}$. The corresponding enthalpies decrease from about 25 to less than $1 \mathrm{cal} . / \mathrm{mol}$, and the transitions are no longer detected for $\mathcal{T} \gtrsim 0.04$ (182 and $192 \mathrm{~K})$ and for $\mathcal{T} \gtrsim 0.12(150$ and $161 \mathrm{~K})$. For $\mathfrak{T}>0.95$ a transition is again observed near $189 \mathrm{~K}$ with $\Delta H \sim 10 \mathrm{cal} . / \mathrm{mol}$.
\end{abstract}

1. Introduction. - The bis-paratoluenesulphonate of 2,4-hexadiyne 1,6-diol, or pTS (also sometimes named TS of TSHD), polymerizes in the solid state, with conservation of crystallinity, up to the pure polymer single crystal stage [1]. Interest first focussed on the polymerization reaction kinetics, which shows an «induction" period up to a polymer content $\mathfrak{T} \sim 0.1$, then an «autocatalytic " range up to $\mathcal{T} \sim 0.9$ in which the rate is enhanced by about 3 orders of magnitude [2]. Another interesting property of pTS is the modulated incommensurable phase recently discovered in the monomer crystal by Robin et al. [3] between a high $T$ phase above $T_{\mathrm{i}} \simeq 200 \mathrm{~K}$, and a low $T$ phase below $T_{1} \simeq 155 \mathrm{~K}$. In the polymer, only high and low $T$ phases are present, with a transition around $190 \mathrm{~K}$ [5]. In partially polymerized crystals, the modulated phase exists only for $\mathfrak{T} \lesssim 0.15$ [6].

A calorimetric study of pTS may then be of interest for several reasons. A phase diagram as a function of $\mathcal{J}$ can be determined. It can also help understand

(*) La version française de cet article a été proposée aux Comptes Rendus de l'Académie des Sciences.

$\left({ }^{* *}\right)$ Laboratoire associé au Centre National de la Recherche Scientifique $n^{\circ} 17$. the order and nature (displacive or order-disorder) of the transitions at $T_{\mathrm{i}}$ and $T_{1}$ : up to now structural work [4], Raman studies [7] and neutron inelastic scattering [8] have failed to give a clear understanding of the processes. Finally, the dependence of $C_{p}$ on $\mathfrak{T}$ at a given temperature may give information about the role and behaviour of polymer chains in the matrix, hence on the polymerization process. We have therefore undertaken a DSC study of microcrystalline pTS powders (prepared by us) and this note reports our first results with a brief discussion.

2. Experimental. - pTS was prepared according to [9] and purified by several recrystallizations in $\mathrm{CH}_{2} \mathrm{Cl}_{2}, \mathrm{CH}_{3} \mathrm{OH}$ mixtures [10]. The microcrystalline powder thus obtained was placed in a thermostat at $60^{\circ} \mathrm{C}$, and sampling at different times yielded the 25 samples studied. $\mathcal{T}$ was measured using two methods which were found in good agreement. For $\mathfrak{T} \lesssim 0.1$, the melting point was measured by DSC [11] : sample weight $\sim 3 \mathrm{mg}$, heating rate $10 \mathrm{~K} / \mathrm{min}$. For $\mathfrak{T} \gtrsim 0.1$, and for cross-checking for several samples in which $0 \lesssim \mathfrak{T} \lesssim 0.1$, the heat evolved during total polymerization of the sample, which is proportional to $1-\mathcal{T}$, was measured by DSC [12] : sample weights were 10 


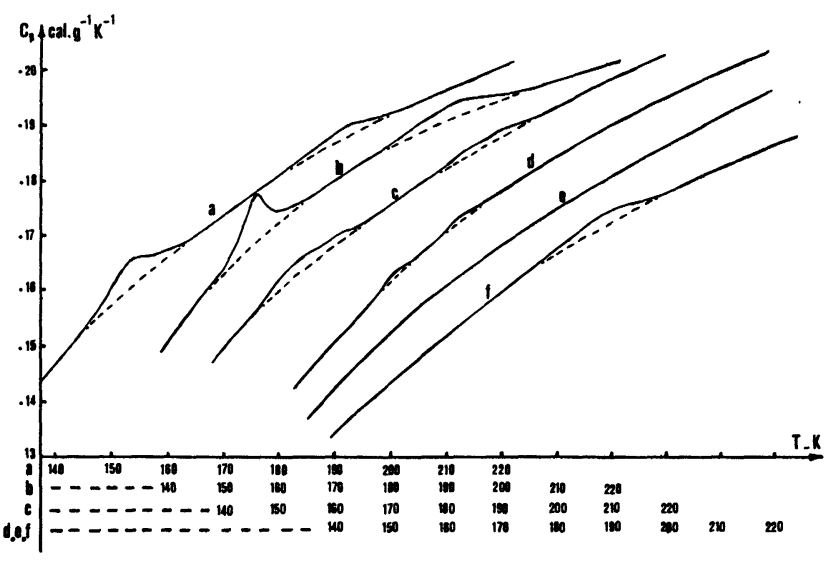

Fig. 1. - Specific heat of partially polymerized microcrystalline pTS samples. Polymer contents : $a(\mathcal{S} \sim 0) ; b(\mathcal{J} \sim 0.002) ; c(0.03)$; $d(0.06) ; e(0.45) ; f(\mathcal{S}>0.99)$.

to $20 \mathrm{mg}$, the heating rate increasing with $\mathfrak{T}$ from 0.31 to $2.5 \mathrm{~K} / \mathrm{min}$.

In pure pTS monomer, a new, metastable phase was found. Most of it transforms into the stable phase by annealing at $60^{\circ} \mathrm{C}$ for $30 \mathrm{~min}$. The new phase is under study.

All measurements were performed on a PerkinElmer DSC 2 microcalorimeter, with a Tektronix 31 attachment. Between 125 and $225 \mathrm{~K}$, the measurement head was cooled with liquid $\mathrm{N}_{2}$ and purged with helium gas. Calibrations in $T( \pm 0.2 \mathrm{~K})$ and in energy $( \pm 0.3 \%)$ were made using the phase transitions of cyclohexane [13] and checked by measuring $C_{p}$ of sapphire from 135 to $225 \mathrm{~K}$ [14]. pTS samples weighing 15 to $25 \mathrm{mg}$ were put in aluminium capsules : the heating rate was $10 \mathrm{~K} / \mathrm{min}$.

3. Results and discussion. - The heat capacity $C_{p}$ of pTS monomer and of 25 samples in which $\mathfrak{T}$ varied from 0.002 to more than 0.995 were measured

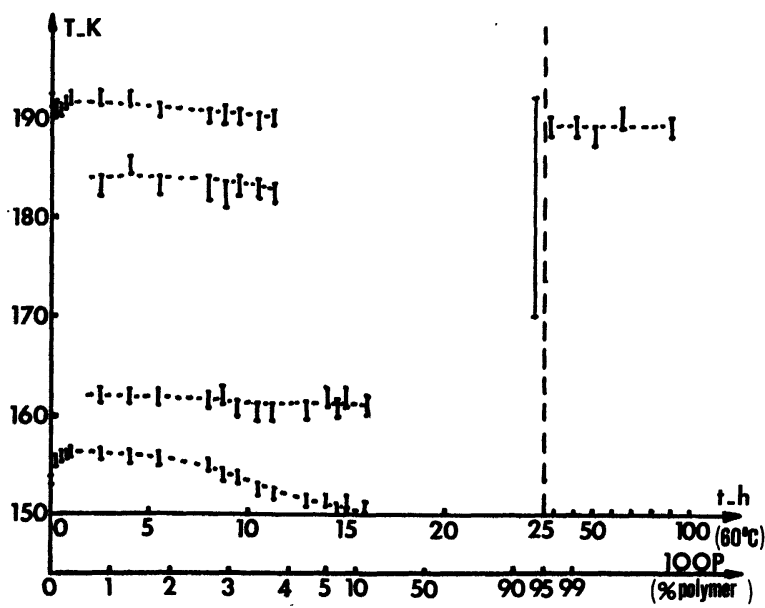

Fig. 2. - Variation with polymer content $\mathfrak{I}$ of the temperature of the maxima of thermal phenomena observed on specific heat $C_{p}(T)$ curves of microcrystalline pTS samples. One scale is linear in heating time (hours) at $60^{\circ} \mathrm{C}$. For $\mathcal{T}$ there is a scale change $\times 100$ at $t=25 \mathrm{~h}(\mathfrak{S} \sim 1$ at $t>25 \mathrm{~h})$. from 136 to $220 \mathrm{~K}$. Figure 2 shows six characteristic $C_{p}(T)$ curves, exhibiting thermal phenomena whose changes depend on $\mathfrak{T}$. For $\mathfrak{T}<0.01$ (Figs. $2 a, 2 b$ ) two transitions are observed, with maxima around 156 and $192 \mathrm{~K}( \pm 1 \mathrm{~K})$ and enthalpies of about 20 and $10 \mathrm{cal} . / \mathrm{mol}$ respectively. They correspond to the limits $T_{1}$ and $T_{\mathrm{i}}$ of the incommensurable phase already observed with X-rays [3] and neutrons [4].

For $0.01<\mathfrak{T}<0.12$, these transitions are split, and the corresponding enthalpies $\Delta H$ decrease when $\mathcal{T}$ increases (Fig. 2e); they are no longer detected when $\Delta H<1 \mathrm{cal} . / \mathrm{mol}$ which occurs near $\mathfrak{T} \sim 0.04$ at 182 and $190 \mathrm{~K}$, and near $\mathcal{T} \sim 0.12$ at 150 and $161 \mathrm{~K}$ (Fig. $2 d$ ). The lowest transition temperature is the only one varying substantially with $\mathfrak{T}$, from 156 to $150 \mathrm{~K}$ (Fig. 3). These values of $\mathfrak{T}$ correspond to the polymerization induction period [2]. No thermal phenomenon distinct from the overall increase of $C_{p}$ rwith $T$ is observed in the autocatalytic range

$$
0.12<\mathfrak{T}<0.95 \text { (Fig. 2e). }
$$

A single broad transition reappears between 170 and $200 \mathrm{~K}$ near $\mathfrak{T}=0.95$, and quickly localizes near $T=189 \mathrm{~K}$ with an enthalpy of $10 \mathrm{cal} . / \mathrm{mol}$ (Figs. $2 f$ and 3). This corresponds to the already known pure polymer transition [5].

For $0.01 \lesssim \mathfrak{T} \lesssim 0.20$, the temperatures of the maxima of the thermal phenomena corresponding to $T_{\mathrm{i}}$ and $T_{1}$ are not identical to the transition temperatures found in X-ray [6] or neutron [4] measurements. The maxima measured in a dynamic DSC experiment as here do no necessarily correspond to the exact transition temperature. In addition, the influence of the grain size of the powder studied cannot be excluded. Experiments on single crystals are in progress.

One can only speculate at present about the origin of endotherms near 161 and $182 \mathrm{~K}$. There may be a succession of modulated phases, commensurate or not; however $\delta$ is always small $[3,4]: \delta \sim 0.06$ at $T_{\mathrm{i}}$.

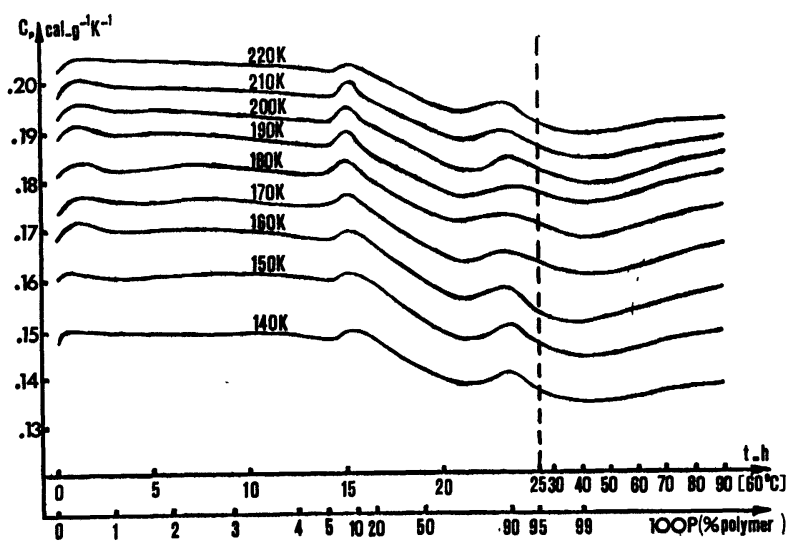

Fig. 3. - Dependence on polymer content $\mathcal{S}$ of the specific heat $C_{p}$ of microcrystalline pTS samples at different temperatures between 140 and $220 \mathrm{~K}$. One scale is linear in heating time (hours) at $60^{\circ} \mathrm{C}$. For $\mathcal{T}$ there is a scale change $\times 100$ at $t=25 \mathrm{~h}(\mathcal{S} \sim 1$ at $t>25 \mathrm{~h})$. 
Alternatively, there may be a macroscopic heterogeneity, as suggested by some neutron data for $\mathfrak{T} \gtrsim 0.2$ average value [15].

Comparing the enthalpies $\Delta H$ found here to those in other materials showing similar transitions - chloranil [16], $\mathrm{Rb}_{2} \mathrm{ZnCl}_{4}$ [17], terphenyl [18] or biphenyl [19] for instance - shows that $\Delta H$ and $\Delta S$ associated with the transitions in pure monomer or polymer pTS are larger than any of them; on the other hand, for $\mathcal{T} \sim 0.1$, the $\Delta H$ at $150 \mathrm{~K}$ is smaller than the small value found for the displacive transition at $38 \mathrm{~K}$ in biphenyl [19]. Preliminary neutron data also show [4] a change in the behaviour of the system near $T_{1}$ when $\mathfrak{T}$ increases from 0.002 to 0.03 . However no soft mode has been detected up to now in perdeuterated pTS with an estimated $\mathfrak{T} \lesssim 0.01$ [8]. pTS might be a system in which the character of the transitions changes continuously with $\mathfrak{T}$.

From $C_{p}(T)$ curves like those displayed in figure 2, the change of $C_{p}$ with $\mathcal{T}$ at constant $T$ (in cal./gK) can be extracted (Fig. 3). The polymer value of $C_{p}$ is always smaller than the monomer value by $5-10 \%$. This may be related to the large variation of thermal expansion coefficient along the $b$ axis, which at these temperatures decreases from $10^{-4} \mathrm{~K}^{-1}$ in the monomer [4] to practically zero in the polymer [20], or to the large increase of sound velocity in that direction [15]. The larger part of the decrease occurs in the autocatalytic range, whose boundaries are marked by maxima of $C_{p}$.

In this note, we limited ourselves to presenting our first calorimetric data, and to sketching avenues for discussion. A further study is in progress. Since completion of this work, measurements of $C_{p}(T)$ from 3 to $300 \mathrm{~K}$ for pure monomer and polymer pTS single crystals have appeared [21]. These data are in good agreement with ours for the corresponding microcrystalline samples.

Acknowledgments. - This work was partially supported by Universite Paris VII. We are grateful to J. Jacques for his interest in our work, and to several colleagues especially J. P. Aimé, M. J. Brienne, R. Chance, G. N. Patel and J. P. Pouget for useful discussions.

\section{References}

[1] Baughman, R. H., in Contemporary topics in polymer science, E. M. Pierce and J. R. Schaerfgen eds. (Plenum Press) 1977, vol. 2, p. 205.

Wegner, G. H., in Proc. NATO-ASI on Molecular Metals, E. E. Hatfield ed. (Plenum Press) 1979, p. 220.

[2] Baughman, R. H. and Chance, R. R., J. Chem. Phys. 73 (1980) 4113 and references therein.

[3] Robin, P., Pouget, J. P., Comes, R. and Moradpour, A., J. Physique 41 (1980) 415.

[4] Aimé, J. P., Bertault, M., Lefebvre, J., Schott, M., WilLIAMS, J. O., to be published.

[5] Bloor, D., Fisher, D. A., Batchelder, D. N., KenNedy, R., Cottle, A. C., Lewis, W. F. and Hurtshouse, M. B., Mol. Cryst. Liq. Cryst. 52 (1979) 83.

[6] Patillon, J. N., Robin, P., Pouget, J. P. and Comes, R., in preparation.

[7] Bertault, M., Krauzman, M., Le Postollec, M., Pick, R. M. et Schotr, M., poster presented at the 69th Faraday Discussion, and in preparation.

[8] Aime, J. P., Lefebvre, J., Pouget, J. P. and Schott, M., in preparation.
[9] WeGNER, G., Z. Naturforsch. 24b (1969) 824.

[10] HÜBER, R., Diplomarbeit, Stuttgart (1976).

[11] Patel, G. N., J. Polym. Sci. Polym. Phys. Ed. 17 (1979) 1591.

[12] Patel, G. N., Chance, R. R., Turi, E. A., Khanna, Y. P., J. Am. Chem. Soc. 100 (1978) 6644.

[13] Aston, J. G., Szasz, G. J. and Fink, H. L., J. Am. Chem. Soc. 65 (1943) 1135.

[14] Gannings, D. C. and Furukawa, G. T., J. Am. Chem. Soc. 75 (1953) 522

[15] GRIMM, H., private communication

[16] Chinara, H. and Masukane, K., J. Chem. Phys. 59 (1973) 5397.

[17] Chandhuri, B. K., Nomoto, K., Atake, T. and Chihara, H., Phys. Lett. 79A (1980) 361.

[18] Cailleau, H. and Dworkin, A., Mol. Cryst. Liq. Cryst. 50 (1979) 217.

[19] Atake, T. and Chihara, H., Solid State Commun. 35 (1980) 131.

[20] Batchelder, D. N., J. Polym. Sci. Polym. Phys. Ed. 14 (1976) 1235.

[21] Engeln, I. and Meissner, M., J. Polym. Sci. Polym. Phys. Ed. 18 (1980) 2227. 